\title{
Management of Humeral Shaft Fracture by Antegrade Interlocking Intramedullary Nail
}

\author{
Md. Tariqul Islam ${ }^{1, *}$, Md. Nazibullah ${ }^{1}$, Anam Ahmed Ripon ${ }^{1}$, Md. Atiqur Rahman Khan ${ }^{2}$, \\ AKM Shaharul Islam ${ }^{1}$ \\ ${ }^{1}$ Department of Orthopedics, TMSS Medical College, Bogura, Bangladesh \\ ${ }^{2}$ Department of Orthopaedics, Monno Medical College Hospital, Gilondo, Manikgonj, Bangladesh
}

Email address:

dr.tariqu129@gmail.com (Md. T. Islam)

${ }^{*}$ Corresponding author

To cite this article:

Md. Tariqul Islam, Md. Nazibullah, Anam Ahmed Ripon, Md. Atiqur Rahman Khan, AKM Shaharul Islam. Management of Humeral Shaft Fracture by Antegrade Interlocking Intramedullary Nail. Journal of Surgery. Vol. 9, No. 2, 2021, pp. 78-81. doi: 10.11648/j.js.20210902.17

Received: January 16, 2021; Accepted: March 11, 2021; Published: April 1, 2021

\begin{abstract}
Background: The humeral shaft fracture is relatively common fracture among the younger and older age groups of people followed by direct or indirect violence. Humeral shaft fractures account for approximately $3 \%$ of all fractures. We have very few data regarding issue. Aim of the study: The aim of this study was to collect information regarding the procedure and outcomes of antegrade interlocking intramedullary nail in treating humeral shaft fracture. Material and methods: This study was carried out during the period from January 2017 to January 2020 at TMSS Medical College and RCH Bogura \& Natore Trauma Center and Hospital, Natore, Bangladesh. Total 15 patients were selected where 10 were male and 5 were female. The study was approved by the ethical committees of mentioned both the institution. Proper written consents were taken from all the participants before starting the main intervention. All data were collected analyzed and disseminated by MS Office program. Results: Postoperative infection were found in 2 patients (13.33\%) and shoulder pain in 1 case (6.67\%). In this study, excellent and good result were accepted as Satisfactory while fair and poor results were regarded as being unsatisfactory. Among them 5 (33.33\%) cases were excellent, $7(46.67 \%)$ cases good, $2(13.33 \%)$ cases fair and $1(6.66 \%)$ cases poor. In this study, overall satisfactory result was found in $12(80 \%)$ cases and unsatisfactory in $3(20 \%)$ cases. Conclusion: The antegraded interlocking intramedullary nail is an effective and technically demanding method for the treatment of humeral shaft fracture.
\end{abstract}

Keywords: Humeral Shaft Fracture, Intramedullary Nailing, Antegrade Interlocking Intramedullary Nail

\section{Introduction}

The shaft of the humerus fracture is commonly occurs in musculoskeletal trauma patients. The incidence of fracture is approximately $1-3 \%$ and usually results from direct or indirect violence. Most of the humeral shaft fracture was successfully treated by conservatively using the functional bracing methods over the past decades. A high percentage of primary healing occurs with conservative methods like hanging cast, U-shaped splint or functional brace, thoracobrachial Spica cast etc. [1]. The rate of nonunion of humeral shaft fracture ranges from $0 \%$ to $8 \%$ with non-operative treatment [2]. Conservative methods have been found to give better result than primary plate fixation in closed injuries. The success of intramedullary nailing techniques for lower limb fractures in the 1980s provoked an interest in the use of this technique for humeral fractures [3]. The reported advantages included minimal surgical incision, avoidance of the fracture exposure, preservation of the neurovasculature and reduced risk of infection etc. Operative treatment has been usually reserved for the treatment of nonunion, for poly-trauma patient bilateral humeral shaft fractures, floating elbow, fractures with neurovascular complications, segmental fractures and pathological fractures. In some cases, operative treatment may cause infection, nonunion and radial nerve palsy [4]. Surgical treatment includes open reduction and internal fixation by plate and open or close reduction and internal fixation by intramedullary nail [5]. Plate fixation requires an extensive exposure with stripping of soft tissues from the bone, but it had given a satisfactory rate of union [6-8]. It also provides less secure fixation especially in osteoporotic bone and crutch walking is required. Elective 
removal of the plate after union can carry an even greater risk of radial nerve injury. Intramedullary stabilization by a close technique does not share these disadvantages. Close intramedullary fixation do not disturb the fracture hematoma, allowing rapid healing [9]. Intramedullary nailing has advantages over the techniques of internal fixation and has been used to maintain the alignment and length of the humerus. Without static locking, however, fixation is often not sufficient rigid and external splintage is needed until union occur. Intramedullary nails may be inserted through either end of the bone. We usually preferred the proximal end. Retrograde insertion is contraindicated for fracture of the distal third of the humerus, fracture in osteoporotic bone [10], or when the medullary canal is less than $10 \mathrm{~mm}$ in diameter [11]. Several antegrade intramedullary nails have been designed to specifically address to the fractures of the shaft of humerus which is the modification of Grosse-Kempftibial nail [12].

\section{Materials and Methods}

This was Retrospective study which was carried out to evaluate the outcome of antegrade interlocking intramedullary nailing in the fracture of the shaft of the humerus and the study was done from January 2017 to January 2020 at TMSS Medical College and RCH Bogura \& Natore Trauma Center and Hospital, Natore, Bangladesh. In total 15 patients with fracture shaft of the humerus were selected consecutively as the study population. Due to lack of easy availability of nail and high cost and study period, total number of cases were in small number. On clinical and radiological basis at the emergency or outpatient department of TMSS \& RCH, Cases were diagnosed as closed fracture shaft of humerus. According to the inclusion criteria of this study, adult patient above 18 years of both sexes, patients with closed fracture shaft of humerus and patients with segmental fractures and fracture less than 4 month of old were included. On the other hand according to the exclusion criteria of the study, children of age $<18$ years, patients with open fracture and patients with pathological fracture as well as physically unfit patients for anesthesia were excluded. The patients were placed in supine with the trunk raised $30^{\circ}$ under general anesthesia. To get free access, the arms were draped separately, to the humerus and shoulders and the fracture sites were opened by standard approach. A $4-5 \mathrm{~cm}$ longitudinal incision was made lateral to the acromion and the deltoid was splitted and exposes the greater tuberosity. A bone awl was introduced just medial to the tip of greater tuberosity $5 \mathrm{~mm}$ posterior to the bicipital groove and a guide wire was then passed cross the fracture and the canal of both proximal and distal fragment was reamed to accept the nail. The appropriate sizes of nail was then fixed with zig and introduce the nail through the hole and extend up to the distal end of proximal fragment and then fracture was reduced and proceed the nail into the distal fragment up to $1-2 \mathrm{~cm}$ above the upper margin of olecranon fossa by hammering. The distal locking screw inserted under the guidance of zig which was directed either anteroposterior or posteroanterior. The proximal locking screw was then inserted under the guidance of zig which was directed from lateral to medial. Autogenous cancellous bone graft was needed if fracture was more than 3 weeks old. Then wounds were closed in usual way and dressings were given. Proper length of the nail was critical because too short nail may not allowed impaction into the distal part or lead to deep insertion of the nail into the humeral head, rendering potential removal of the nail extremely difficult. On the other hand, too long nail may keep the fracture ends apart and cause impingement of the shoulder.

Table 1. Constant and Murley score of functional assessment.

\begin{tabular}{ll}
\hline Items & Score \\
\hline Pain (15) & 15 \\
None & 10 \\
Mild & 5 \\
Moderate & 0 \\
Severe & \\
Activities of daily living (20) & 4 \\
Full work & 4 \\
Full recreation/ sports & 2 \\
Unaffected sleep & \\
Hand position (25) & 2 \\
Up to waist & 4 \\
Up to xiphoid & 8 \\
Up to top of head & 10 \\
Above head & \\
Range of Motion (40) & 10 \\
Abduction & 10 \\
Forward elevation & 10 \\
Internal rotation & 10 \\
External rotation & \\
\hline
\end{tabular}

Table 2. Assessment grades of the function.

\begin{tabular}{ll}
\hline Evaluation factor & Range \\
\hline Excellent & 80 to 100 points \\
Good & 60 to 79 points \\
Fair & 40 to 59 Points \\
Poor & 0 to 39 Points \\
\hline
\end{tabular}

Table 3. Grades of radiological union.

\begin{tabular}{ll}
\hline Number of weeks & Evaluation \\
\hline 12 weeks & Excellent \\
16 weeks & Good \\
20 weeks & Fair \\
More than 20 weeks & Poor \\
\hline
\end{tabular}

Table 4. Assessment grades according to Pandey, 2003.

\begin{tabular}{ll}
\hline Grades & Features \\
\hline & Fracture Union- in 12 weeks \\
Excellent & Functional result- excellent \\
& No infection \\
& No radial nerve palsy \\
& Fracture union - in 16 weeks \\
& Functional Result-good \\
Good & No infection \\
& No radial nerve palsy \\
& Fracture union - in 20 weeks \\
& Functional Result-good \\
& No infection \\
& No radial nerve palsy \\
& Union after 20 weeks or nonunion \\
& Functional Result-Poor \\
& Persistent infection \\
& Persistent radial nerve palsy \\
\hline
\end{tabular}

In this study satisfactory outcomes indicate the excellent or 
good outcomes whereas unsatisfactory outcomes indicated the fair or poor results. All data were collected analyzed and disseminated by MS Office program.

\section{Results}

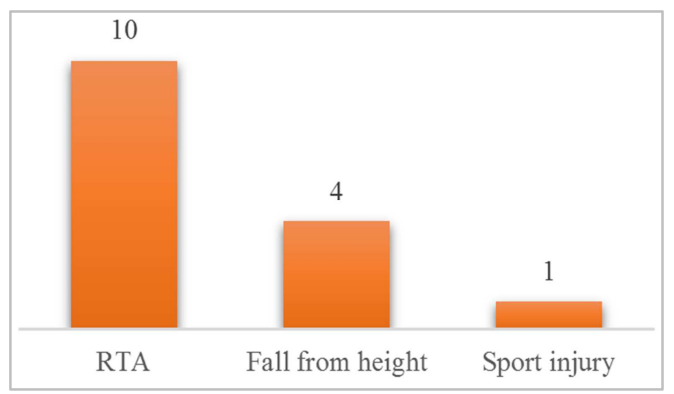

Figure 1. Mechanism of injury of participants $(n=15)$.

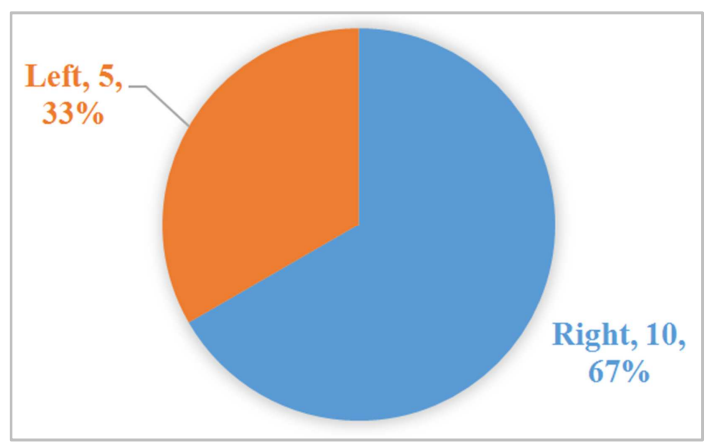

Figure 2. Side of injury of participants $(n=15)$.

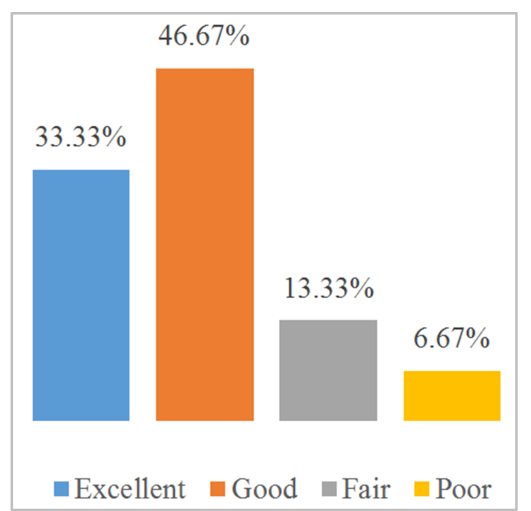

Figure 3. Outcomes among the participants $(n=15)$.

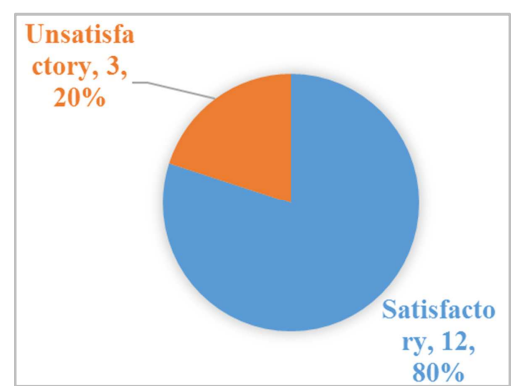

Figure 4. Outcomes in brief among the participants $(n=15)$.

In this study 10 patients were treated by closed reduction and internal fixation by interlocking intramedullary nail and 5 patients were treated by open reduction and internal fixation by interlocking intramedullary nail. Minimum follow up time was 6 months and maximum 18 months. Most of the patients were from under 21-30 years of age group (33\%) while next common age group $31-40$ years $(26.67 \%)$. The mean age incidence was $37.27( \pm 14.09)$. This figure was compared with those seen by other workers. The young adult age group points to higher rate of mobility as well as social violence. Male population was constituted $66.67 \%$ of causes while the females made up remaining $33.33 \%$. Males being the major working force of our Society and are thus more consistently exposed to external environment. Farmers were affected more than others $(26.67 \%)$ and second next group were housewife in this series. This is due to most our male population are farmers and females are housewife. Road traffic accident was the most common cause of the injuries in this study $66.67 \%(\mathrm{n}=10)$. Second common cause was fall from height counting $26.67 \%$ $(\mathrm{n}=4)$ and the last one cause was sport injury where the ratio was $6.67 \%(n=1)$. Right side was affected more $(66.67 \%)$ than left side $(33.33 \%)$. Most fracture occurred in the middle third of the shaft of humerus $(46.67 \%)$, followed by lower third $(33.33 \%)$. In this series the period between time of injury and operation ranged from 1 week to 6 weeks with an average 4 $( \pm 1.36)$ weeks. Postoperative hospital stay in this series was minimum 5 days and maximum 14 days Mean postoperative stay $9( \pm 2.59)$ days. Union time of fractures in this series was minimum 12 weeks and maximum 24 weeks with the Mean $15.6( \pm 3.56)$ weeks. Union as per fracture site took the longest time in the middle third fracture's group with a mean of 16 $( \pm 4.16)$ weeks and shortest in upper third with a mean of 12 $( \pm 0)$ weeks. Postoperative infection (Superficial wound infection) were found in 2 patients $(13.33 \%)$ and shoulder pain in 1 case $(6.67 \%)$. For evaluation of result, functional outcome with constant and Murley scoring and time taken for radiological union were followed. Moreover, this system included infection as one of the parameters for assessment of outcome. Excellent and good result were accepted as Satisfactory while fair and poor results were regarded as being unsatisfactory. Among them $5(33.33 \%)$ cases were excellent, 7 (46.67\%) cases good, 2 (13.33\%) cases fair and $1(6.66 \%)$ cases poor. In this study, overall satisfactory result was found in $12(80 \%)$ cases and unsatisfactory in $3(20 \%)$ cases.

\section{Discussion}

The aim of this study was to collect information regarding the procedure and outcomes of antegrade interlocking intramedullary nail in treating humeral shaft fracture. This study was carried out during the period from January 2016 to January 2018 at TMSS Medical College and RCH Bogura, Bangladesh. Total 15 patients were selected where 10 were male and 5 were female. The study was approved by the ethical committees of mentioned both the institution. Proper written consents were taken from all the participants before starting the main intervention. Although the non-operative treatment of humeral shaft fractures has been traditionally 
regarded as the "gold standard", more and more of these fractures are being treated operatively [13]. Both locking nailing and locking plating are methods of choice for fractures of the proximal and middle third of the humerus. Non-surgical treatment result in a higher incidence of union and fewer complications than open reduction and internal fixation. Open reduction with internal fixation may be definite indication like nonunion, poly-trauma patients, bilateral humeral shaft fractures, floating elbow, fractures with neurovascular complications, segmental fractures and pathological fractures. Fractures of the humeral shaft can be fixed internally by plate and Screws, intramedullary nails, or external fixation devices. In this series postoperative infection (Superficial wound infection) in 2 patient, which was controlled by regular dressing and sensitive antibiotic and shoulder pain in 1 case. The main problems of antegrade nailing for humeral fractures are three: Violation of the rotator cuff, soft tissue injury around the shoulder and distal locking [14]. In our study, postoperative infections (Superficial wound infection) were found in 2 patients $(13.33 \%)$ and shoulder pain in 1 case $(6.67 \%)$. For evaluation of result, functional outcome with constant and Murley scoring and time taken for radiological union were followed. Moreover, this system included infection as one of the parameters for assessment of outcome. Excellent and good result were accepted as Satisfactory while fair and poor results were regarded as being unsatisfactory. Among them 5 $(33.33 \%)$ cases were excellent, $7(46.67 \%)$ cases good, 2 $(13.33 \%)$ cases fair and $1(6.66 \%)$ cases poor. In this study, overall satisfactory result was found in $12(80 \%)$ cases and unsatisfactory in $3(20 \%)$ cases. Modifications of the surgical technique with sophisticated nail designs have been proposed in order to overcome problems of the cuff, but no further studies have validated these proposals. In my study infection rate was $13.33 \%$ due to our operation theatre facilities ware not adequate and shoulder pain $6.67 \%$ might be due to subacromial bursitis and technical operative fault like protrusion of nail. As this procedure is minimally invasive with less chance of infection, implant failure and soft tissue handling with rigid fixation, we can provide early ambulation to patient. So they can be able to start their working activity comparatively other than any other fixation like plating.

\section{Conclusion \& Recommendation}

For the management of humeral shaft fractures the outcome of interlocking intramedullary nail is revolutionary. The humeral shaft fracture, especially in non-union, transverse fracture, segmental fractures, in poly-trauma patient and in patient who needs early function, antegrade interlocking intramedullary nailing is the satisfactory method for internal fixation. The findings of this study may be helpful in the treatment arena of orthopedics and in further studies. For getting more specific information we would like to recommend for conducting similar more studies in several places with larger sized sample.

\section{References}

[1] Ouyang H, Xiong J, Xiang P, Cui Z, Chen L, Yu B (2013) Plate versus intramedullary nail fixation in the treatment of humeral shaft fractures: an updated meta-analysis. J Shoulder Elbow Surg Am Shoulder Elbow Surg 22 (3): 387-395. doi: 10.1016/j.jse.2012.06.007.

[2] Ma J, Xing D, Ma X, Gao F, Wei Q, Jia H, Feng R, Yu J, Wang J (2013) Intramedullary nail versus dynamic compression plate fixation in treating humeral shaft fractures: grading the evidence through a meta-analysis.

[3] Suzuki T, Hak DJ, Stahel PF, Morgan SJ, Smith WR (2010) Safety and efficacy of conversion from external fixation to plate fixation in humeral shaft fractures. J Orthop Trauma 24 (7): 414-419. doi: 10.1097/BOT.0b013e3181c673a6.

[4] Sarahrudi K, Wolf H, Funovics P, Pajenda G, Hausmann JT, Vécsei V. Surgical treatment of pathological fractures of the shaft of the humerus. J Trauma 2009; 66: 789-94.

[5] Walker M, Palumbo B, Badman B, Brooks J, Van Gelderen J, Mighell M (2011) Humeral shaft fractures: a review. J Shoulder Elbow Surgery Am Shoulder Elbow Surg 20 (5): 833-844. doi: 10.1016/j.jse.2010.11.030.

[6] Ngai SL, Ip KC, Lee KB, Shen WY, Chan Ben. Minimally invasive fixation for proximal humeral fracture: A review on the use of T2 proximal humeral nail. J Orthop Trauma Rehabil 2013; 17: 66-70.

[7] Mahabier KC, Vogels LM, Punt BJ, Roukema GR, Patka P, Van Lieshout EM (2013) Humeral shaft fractures: retrospective results of non-operative and operative treatment of 186 patients. Injury 44 (4): 427-430.

[8] Whatling GM, Nokes LD. Literature review of current techniques for the insertion of distal screws into intramedullary locking nails. Injury 2006; 37: 109-19.

[9] Dimakopoulos P, Papadopoulos AX, Papas M, Panagopoulos A, Lambiris E. Modified extra rotator-cuff entry point in antegrade humeral nailing. Arch Orthop Trauma Surg 2005; 125: 27-32.

[10] Marsh JL, Slongo TF, Agel J, Broderick JS, Creevey W, DeCoster TA, et al. Fracture and dislocation classification compendium-2007: Orthopaedic trauma association classification, database and outcomes committee. J Orthop Trauma 2007; 21 (Suppl 10): S1-133.

[11] Kurup H, Hossain M, Andrew JG (2011) Dynamic compression plating versus locked intramedullary nailing for humeral shaft fractures in adults. The Cochrane database of systematic reviews. doi: 10.1002/ 14651858. CD005959.pub2. DOI: $10.4103 / 09736042.114233$.

[12] Gradl G, Dietze A, Kääb M, Hopfenmüller W, Mittlmeier T. Is locking nailing of humeral head fractures superior to locking plate fixation? Clin Orthop Relat Res 2009; 467: 2986-93.

[13] Cheng HR, Lin J. Prospective randomized comparative study of antegrade and retrograde locked nailing for middle humeral shaft fracture. J Trauma 2008; 65: 94-102.

[14] Blum J, Karagül G, Sternstein W, Rommens PM. Bending and torsional stiffness in cadaver humeri fixed with a self-locking expandable or interlocking nail system: A mechanical study. J Orthop Trauma 2005; 19: 535-42. 